By Joel Brown and David Smith

\title{
Land Ecology Essay I: The Siren Song of the Finish Line
}

0

r. Joel Brown is the National Program Leader for the USDA Natural Resources Conservation Service's National Ecological Site Team located at the Jornada Experimental Range in Las Cruces NM. He regularly writes about rangeland issues on the Land Ecology blogi. "Land ecology" honors the holistic approach to the knowledge needed to support land stewardship into our increasingly uncertain future. David Smith is the Deputy Chief for Soil Science and Resource Assessment with the USDA Natural Resources Conservation Service in Washington, DC.

\section{The Siren Song of the Finish Line}

Homer's Odyssey is the tale of an epic journey in which the hero, Ulysses, faces many trials in his 10-year journey as he returns home to his family after the Trojan War (the one with the horse). Ulysses' experiences are generally regarded to be a means of conveying to the listener or reader the pitfalls of arrogance, and the value of persistence, in pursuing noble ends. A particular favorite trial, near-disaster, and recovery is the story of the Siren Song-beautiful creatures promising paradise, but with the reality of death and destruction. Ulysses was a character imbued with heroic qualities, and even with those attributes, had to call on every bit of guile and luck to survive - the point being that even noble heroes have to fight for survival. Another important lesson of the tale is that even well-intentioned heroes can get distracted, imperiling their goals and their followers.

Land ecology involves lots of people doing lots of different things. While most of us tend to think primarily about the science and technical perspectives, the spatial and temporal scale of the practice of land ecology requires that almost everyone participate at some level. Each of those groups and their activities require resources. One of the most challenging aspects of land ecology is to get the balance right; in particular, the balance between the generation of new information and the application of existing accepted knowledge. At one end of the spectrum is the valid argument that we can always learn more but we should not wait to get on with the job. At the opposite end is the rationale for a learning-based approach — as we do more, we learn more, and we should constantly be revising the information base. These questions are complicated by the lack of a centralized decision-making structure in most landscapes; there are competing uses and groups, many of whom don't even know they are in the mix.

While real decision points often are difficult to recognize a priori, we are likely at one in land ecology in North America, especially in agriculture dominated landscapes. The National Cooperative Soil Survey (NCSS) has been a model for effective use of taxpayer funds to collect, store, and disseminate information relative to land use and management. ${ }^{1}$ It has been so good in fact, that it has just about completed the initial soil survey (Fig. 1). Although it is certainly not perfect, the information associated with the NCSS is accurate, highly accessible, and exceptionally useful. There are some gaps and a need for refinements (particularly in areas of land use change), but on the whole, this effort represents a standard that most of the rest of the world can only dream about. The measured and interpreted information in this survey is far from an esoteric or academic exercise; basic information about soil performance and properties provides a basis for decision making for farmers; agribusiness; and local, state, and federal

$\overline{\mathrm{i}}$ To read more of Joel's essays, visit http://landecology.org/. 


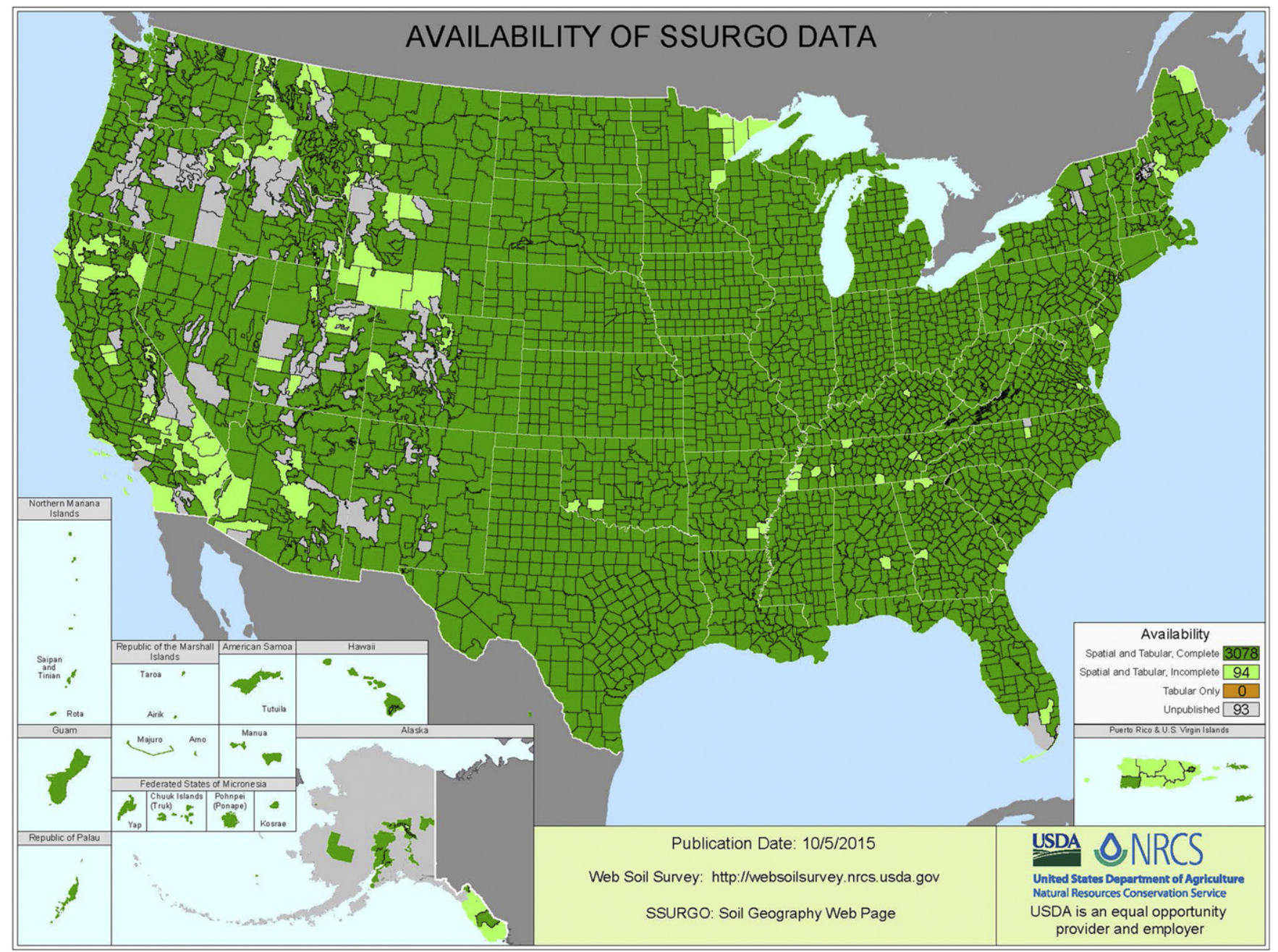

Figure 1. Availability of soil property information in the Soil Survey Geographic Database for the United States and Territories. All information in the SSURGO Database meets the standards of the National Cooperative Soil Survey.

governments. On the global level, readily available resource information provides a competitive advantage that helps ensure efficiency in production systems and government programs, even when the analysis is confined to onsite benefits. ${ }^{2}$ Generally, the return on investment is far greater than most other potential agriculture investments. ${ }^{3}$

While we can be confident that the existing information in the NCSS has been well worth the investment, what is next? One school of thought is "Well, it's done. Now we can close the program and save the money." Another, almost as ill-conceived idea, is "Good, now we can use the money to apply more conservation practices." Both of these illogical options are based on the assumption that we have garnered sufficient knowledge from the existing work to solve conservation challenges and that the problems of the 20th century are also the problems of the 21st century. Neither of these premises requires much effort to invalidate, simply because our existing interpretations are based on some pretty shaky assumptions about climate stability. There is way more than enough evidence to dictate that we re-examine the way we interpret our existing data.
Added to climate change implications are a variety of changing assumptions about what we expect from land. Most of our existing interpretations are limited to ideas about how to optimize and maintain production of a fairly narrow range of commodities. As the pressure on land and ecosystems increases to produce not only more but a wider variety of goods and services, our interpretations have to consider a broader array of inputs, processes, and outputs. For example, we struggle mightily with trying to predict the effects of changes in land use and management on hydrologic processes when we only consider landscapes as collections of fields. Land ecology and management is, without overstating it, complicated.

Initiatives to reinterpret existing soil and vegetation information that we have collected as part of the existing NCSS effort, as well as emerging ideas about how to extend the concepts, are loaded with promise. Far from winding down, the early efforts at rethinking our basic assumptions and developing new ideas are really starting to pay off. Not the least of which is the ecological site (ES) effort that the NCSS has elevated in importance. ${ }^{4}$ 
The development of ES has been a priority for USDA Natural Resources Conservation Service for a couple of decades; if you consider the antecedent range sites, it has been a part of Soil Conservation Service/NRCS since inception. The elevation of ES as an important collaborative effort among NRCS, Forest Service, and Bureau of Land Management has only increased the value of both existing and ongoing soil survey information. The NCSS has recently made ES work a part of its standing committee structure for planning and implementing soil survey projects. The true value of the development and description of ES is that it provides a basis for resource inventory and predictions of the effects of management that underlie the implementation of conservation programs and practices.

This acceleration of ES work is a good example of the need to continually refine and update soil survey information. Our previous iteration of site interpretations, range sites, was based on a hypothesized "climax" plant community for a group of soil properties. As we have shifted to a more dynamic approach to describing soil-vegetation interactions (as expressed in state-and-transition models), we have had to refine, sometimes significantly, the soil properties that we group together. Introducing new ideas as part of the ES effort has changed how we have mapped and described soils over the past 20 years. Likewise, the information we have been able to accumulate as part of the soil survey has changed how we group soil properties and describe their vegetation dynamics as part of ES. In all cases, how we conduct soil survey and ecological site work is based on what users are asking for. Not only has the scientific basis for measuring and mapping changed, but our ideas about ecosystem services have changed substantially since the NCSS began.
Continually refining soils and vegetation information, including how we deliver it to users, is necessary to address those new needs.

The questions that appear on the horizon require not just the existing ideas, but demand that we put some serious effort into developing completely new, and sometimes seemingly contradictory, approaches. So the idea that we can "finish" the soil survey - call it a day and head to the house-may be appealing to bean counters, it's a siren song that we have to actively resist. Like Ulysses strapped himself to the mast, we can and should take part in celebrating completing a portion of the journey, but also actively and aggressively devise and defend plans to keep moving forward-continually refining and improving our information for new uses and new users. And, most importantly, to making that information serve the goal of better natural resource management.

\section{References}

1. Miller, B.A. 2012. The need to continue improving soil survey maps. Soil Horiz 53:11-15.

2. Giasson, E., C. van Es, A. van Wambeke, and R.B. Bryant. 2000. Assessing the economic value of soil information using decision analysis techniques. Soil Sci 165:971-978.

3. Pradhan, A. 2009. Economic benefits of the National Cooperative Soil Survey Program. [Ph.D. Thesis Publication No. 3381204]. Morgantown, WV, USA: West Virginia University. [146 pp.].

4. Johanson, J., AND J.R. Brown. 2012. Ecological site development: accelerating the effort. Rangelands 34:29-31.

Rangelands (37)6:241-243

doi: $10.1016 /$ j.rala.2015.10.005

(C) 2015 The Society for Range Management 